\title{
Development of a Liposomal Dosage Form for a New Somatostatin Analogue
}

\author{
E. SANAROVA*, A. LANTSOVA, N. OBOROTOVA, A. POLOZKOVA, M. DMITRIEVA, O. ORLOVA, L. NIKOLAEVA, \\ L. BORISOVA AND Z. SHPRAKH
}

Research Institute of Experimental Diagnostics and Therapy of Tumors, Federal State Budgetary Institution "N.N. Blokhin National Medical Research Center of Oncology" of the Ministry of Health of the Russian Federation, Moscow 115478, Russia

Sanarova et al.: Technology Development of AS Liposomes

\begin{abstract}
A new pentapeptide analogue of somatostatin was synthesized and preliminary studies demonstrated that this analogue possessed antitumor activity on transplanted solid tumours of mice. Due the analogue's insolubility in water, a liposomal formulation was attempted to increase bioavailability of the drug, to administer intravenously and to improve selectivity towards the tumor cells. This study employed the somatostatin analogue, egg lecithin, 1,2-distearoyl-sn-glycero-3-phosphoethanolamine- $\mathrm{N}$-[methoxy (polyethyleneglycol)-2000, cholesterol and sucrose. Model compositions of the somatostatin analogue liposomal dosage form were prepared using the lipid film rehydration method. All samples obtained were characterized by measuring size of liposomes, pH of the liposomal dispersion, and assay of somatostatin analogue incorporated in the liposomal bilayer. Efficiency of the formulation was investigated on models of breast adenocarcinoma Ca-755. During experimental development of the somatostatin analogue liposomal formulation, an optimal composition was established, which included egg lecithin and 1,2-distearoyl-snglycero-3-phosphoethanolamine- $\mathrm{N}$-[methoxy(polyethyleneglycol)-2000 in the 72/1 molar ratio. Influence of extrusion on the quality of liposomal preparations was studied. It was shown that to reach an optimal liposome size of about $150 \mathrm{~nm}, 7$ extrusion cycles were necessary. In addition, while assessing the stability of the somatostatin analogue liposomal dispersion during storage it was found that somatostatin analogue was extremely unstable in liquid form, thus, to produce a stable formulation, lyophilization became necessary. The liposomal formulation when tested on transplanted tumours in mice, more than $60 \%$ tumor growth inhibition was observed at $5 \mathrm{mg} / \mathrm{kg}$ dose and more than $80 \%$ tumor growth inhibition at $20 \mathrm{mg} / \mathrm{kg} \mathrm{dose}$. These findings indicated that further efforts are required to improve this liposomal formulation to develop the somatostatin analogue in to a potential antitumor drug.
\end{abstract}

Key words: Somatostatin analogue (AS), liposomes, extrusion, stability

Despite a wide range of chemotherapeutic drugs used in actual therapy of malignant tumours, the main limitation of use in clinical practice is the expressed toxicity of most of these. There existed a need to search, study and develop dosage forms of drugs with high antitumor activity and low expressed side effects. Such dosage forms are needed to deliver analogues of a peptide hormone of hypothalamus, somatostatin, which inhibited release of human growth hormone, thyrotropin, glucagon, insulin, and also suppressed proliferation of many normal and tumor cells $\mathrm{s}^{[1]}$.

Analogues of somatostatin such as octreotide and lantreotide are under clinical investigation ${ }^{[2]}$. Indications for their use in oncology are, endocrine tumours of digestive tract and pancreas and therapy of androgen-

*Address for correspondence E-mail: sanarova8686@mail.ru

January-February 2019 independent prostate cancer. Thus, synthesis of new analogues of the somatostatin group, investigation of the mechanisms of action of their antiproliferative activities, and development of dosage forms are the new directions of research in this field.

In the Laboratory of Chemical Synthesis of the Institute of Experimental Diagnostics and Therapy of Tumours, N. N. Blokhin Russian Cancer Research Center, a new pentapeptide analogue of somatostatin

This is an open access article distributed under the terms of the Creative Commons Attribution-NonCommercial-ShareAlike 3.0 License, which allows others to remix, tweak, and build upon the work non-commercially, as long as the author is credited and the new creations are licensed under the identical terms

Accepted 16 November 2018

Revised 16 April 2018

Received 27 March 2017

Indian J Pharm Sci 2019;81(1):146-149 
(AS) was synthesized. Preliminary studies of hormonal activity of AS have shown that it suppressed secretion of somatotropic hormone and prolactin. Also high antitumor activity of AS on the intertwined solid tumours on mice was reported.

For reducing side effects and increasing therapeutic efficacy, a liposomal formulation of AS was attempted. The choice of liposomes as a delivery system for AS was made due to their positive characteristics, such as increase in bioavailability of hydrophobic substances ${ }^{[3,4]}$, increase of therapeutic efficacy of newer drugs and other widely applied antitumor substances ${ }^{[5]}$, especially due to improving of selectivity of the $\operatorname{action}^{[6,7]}$.

AS was purchased from the Laboratory of Chemical Synthesis of Institute of Experimental Diagnostics and Therapy of Tumours, N. N. Blokhin NMRCO, Russia. Egg lecithin (EL) and 1,2-distearoyl-sn-glycero-3phosphoethanolamine-N-(methoxy(polyethylenegly col)-2000 (PEG-2000-DSPE) were purchased from Lipoid (Germany), cholesterol was purchased from Sigma (Germany); sucrose and chloroform were purchased from Chimmed (Russia).

AS is a white or slight yellowish odourless crystal powder with a melting point in the range of $121-125^{\circ}$, which is practically insoluble in water, very slightly soluble in diluted mineral acids and alkalis, slightly soluble in $95 \%$ ethyl alcohol and acetone, soluble in chloroform. Its molecular weight is $1016.2 \mathrm{~g} / \mathrm{mol}$.

Model compositions of AS liposomal dosage form were prepared using the lipid film rehydration method modified for hydrophobic substances. Ingredients used to form liposomal bilayer (EL, cholesterol and PEG-2000-DSPE) were dissolved in chloroform. Chloroform solution of AS was sonicated in an ultrasonic bath Trassonic (Elma, Germany) for 5-10 min, and then added to solution of lipids. Obtained mixture was filtered through the Pall nylon membrane filter (Pall Eurasia Ltd., Russia), pore size $0.22 \mu \mathrm{m}$, and transferred to a round-bottom flask. The solvent was removed at $+37^{\circ}$ using a rotary evaporator Büchi Rotavapor R-200 (Büchi Labortechnik AG, Switzerland) to form a homogeneous semi-transparent lipid film. Obtained film was additionally dried in a vacuum desiccator to complete removal of organic solvent and then hydrated with a solution of sucrose to form a multilamellar vesicle dispersion. Dispersion was extruded on pneumatic extruder Lipex (Northern
Lipids; Lipex Biomembranes, Canada) sequentially through nylon filter Pall membranes, pore sizes 1.20, 0.45 and $0.22 \mu \mathrm{m}$.

The following parameters of all obtained samples were characterized, size of liposomes measured by nanosizer Nicomp 380 Submicron Particle Sizer (Particle Sizing Systems, USA), pH of the liposomal dispersion measured potentiometrically using a $\mathrm{pH}$-meter Hanna 211 (Hanna Instruments, Germany), and assay of AS incorporated in the liposomal bilayer was determined by spectrophotometry using a standard solution at wavelength $282 \pm 3 \mathrm{~nm}$. Also it was observed that other ingredients in the composition of liposomes, such as lecithin, cholesterol and PEG-2000-DSPE, absorbed light at the same wavelength. Therefore, measurements were performed in comparison with a blank solution, which consisted of empty liposomes, prepared similarly to the AS liposome preparation without AS.

Because AS is a hydrophobic substance and it is added directly into the lipid bilayer in the preparation of liposomes, the amount of incorporated drug (ID) was determined as the ratio of AS concentration in the liposome dispersion after filtration to AS concentration in the liposome dispersion after hydration of the lipid film. ID is expressed as a percent.

Biological studies were carried out on tumor-bearing first generation $\mathrm{F} 1(\mathrm{C} 57 \mathrm{Bl} / 6 \times \mathrm{DBA} / 2)$, as well as outbred mice, female weighting 20-22 g, obtained from the animal house and kept on a standard diet. The animals were given cubed feed and water ad libitum. All experiments were performed according to the ethics of Biomodel and laboratory animal experiments adopted by the N. N. Blokhin $\mathrm{NMRCO}^{[8]}$. Efficiency of antitumour therapy was investigated on models of breast adenocarcinoma Ca-755. Ca-755 was transplanted to $\mathrm{F} 1$ hybrid mice by intramuscular injection of homogenized tumor into the right shin issue diluted 1:10 by 199 medium (PanEco, Russia). The animals were grouped to ensure statistically reliable results are obtained, the control group comprised of 10 mice and the experimental group comprised of 8 mice.

Systemic administration of AS was made $48 \mathrm{~h}$ after tumor transplantation. Liposomal AS injected to mice intravenously once either at a dose of $5 \mathrm{mg} / \mathrm{kg}$ or at a dose of $20 \mathrm{mg} / \mathrm{kg}$. Antitumor efficacy was evaluated by tumor growth inhibition (TGI \%) and survival of experimental animals compared with non-treated 
control group. In the determination of TGI, the volume of the tumor was calculated, first, as the product of three maximally reciprocal sizes of the tumor node (length, width and height) in each animal, and then the average tumor volume in the group was calculated.

Statistical significance of antitumor effect compared to the control group was estimated by Fischer-Student method. Differences between parallel groups were considered to be statistically significant at $\mathrm{p} \leq 0.05$.

Composition of liposomal AS was based on mixture of EL and cholesterol providing both biocompatibility and stability of delivery vehicles supplied, with phospholipid-conjugated polyethylene glycol (PEG2000-DSPE) to overcome fast clearance vesicles by cells of the reticuloendothelial system. Based on these components, 6 formulations containing different amounts of excipients were prepared. Results of mean liposome size, $\mathrm{pH}$, concentration and ID determination for each composition are presented in Table 1. Results showed that according to above-mentioned parameters (high level of ID- $96 \%$ and an acceptable liposome size- $151 \mathrm{~nm}$; fig. 1 and fig. 2) the most appropriate was the composition 3 , without cholesterol, which was used for further studies.

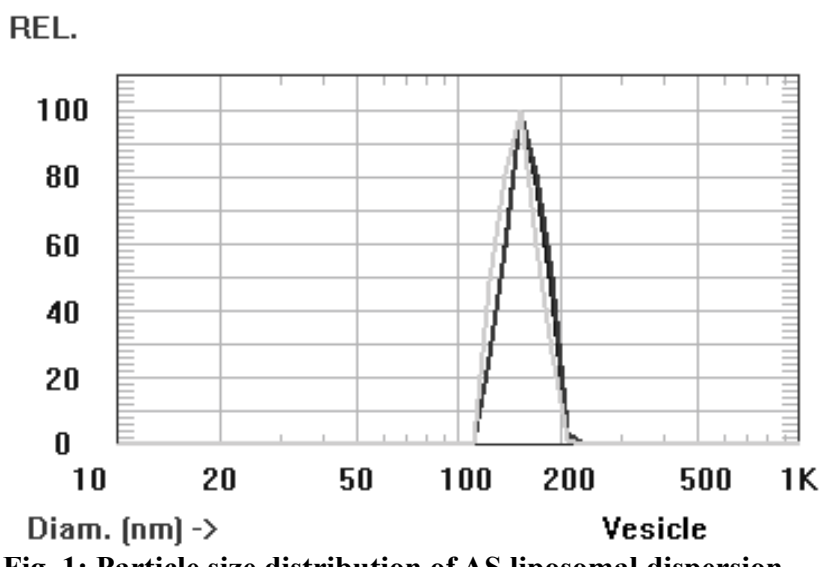

Fig. 1: Particle size distribution of AS liposomal dispersion Size of liposomes were measured on nanosizer Nicomp 380 Submicron Particle Sizer (Particle Sizing Systems, USA) coupled with Nicomp PSS WC370 MFC Application v.1.0.001 computer software, in "vesicle mode"
Studies were conducted to determine the optimal number of extrusion cycles needed to produce AS liposomes. Due to the fact that abundant increase of extrusion time caused activation of liposomal phospholipid peroxidation, increase of their size due to Ostwald ripening and decrease of EE, the minimum time (number of cycles) of extrusion to obtain the liposomes of required diameter (100-150 nm) was determined. Liposomal dispersion was loaded at volume $10 \mathrm{ml}$, extruded and sampled after each extrusion cycle. Experimental samples were evaluated for the change of mean vesicle size. This experiment showed that the optimum criterion, liposome size was reached during 7 extrusion cycles (Table 2). The maintenance of extrusion is not appropriate, because it does not lead to decrease of liposome size, and the influence of negative factors may be exacerbated.

To assess the stability of liposome dispersion obtained above by the chosen technology, the quality indicators monitoring was performed (liposome size, $\mathrm{pH}$, concentration of the drug in the liposome dispersion) when stored at $4^{\circ}$. After 3 weeks of storage, size of liposomes and drug concentration in the liposome

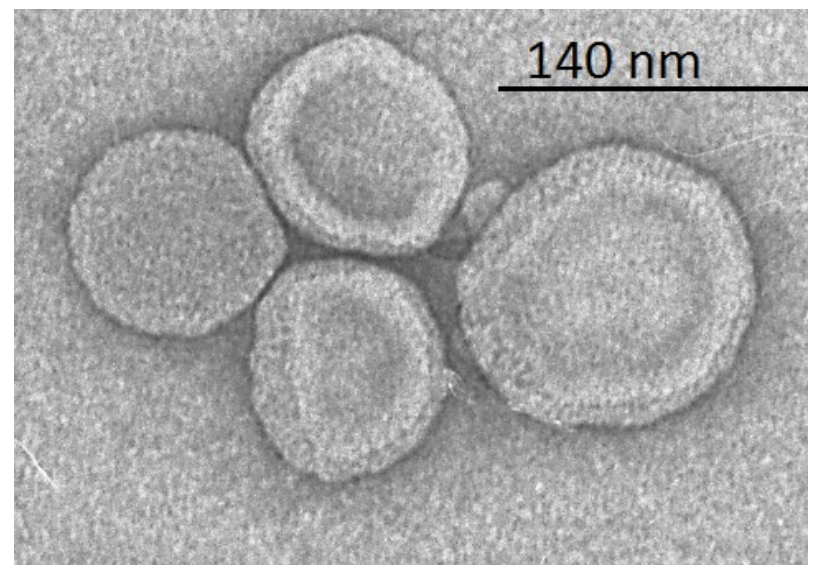

Fig. 2: ASM image of AS liposomes

On a collodion-carbon film-coated substrate pattern contrasted with $1 \%$ uranyl acetate and viewed in a JEM-100CX (Jeol, Japan) electron microscope at a magnification of 20000 times with a scanning resolution 1200 dpi. For the accurate calculation of the increase, were used photos of latex particles with average diameter of $109 \pm 3 \mathrm{~nm}$

\section{TABLE 1: COMPOSITION OF AS LIPOSOMAL DOSAGE FORMS}

\begin{tabular}{lccccc}
\hline Composition no. & $\begin{array}{c}\text { The molar ratio of } \\
\text { EL:cholesterol:PEG-2000-DSPE }\end{array}$ & $\begin{array}{c}\text { Average vesicle size } \\
(\mathrm{nm}) \pm \text { SEM }\end{array}$ & $\mathrm{pH} \pm \mathrm{SEM} \%$ ID \pm SEM $\begin{array}{c}\text { Concentration AHHS, } \\
(\mathrm{mg} / \mathrm{ml}) \pm \text { SEM }\end{array}$ \\
\hline 1 & $18: 14: 1$ & - & $7.1 \pm 0.1$ & $83 \pm 1.0$ & $0.55 \pm 0.02$ \\
2 & $52: 16: 1$ & $192 \pm 14$ & $6.9 \pm 0.1$ & $78 \pm 0.5$ & $0.52 \pm 0.04$ \\
3 & $72: 0: 1$ & $151 \pm 11$ & $7.2 \pm 0.2$ & $96 \pm 1.6$ & $0.96 \pm 0.01$ \\
4 & $72: 14: 1$ & $149 \pm 14$ & $7.1 \pm 0.1$ & $79 \pm 1.1$ & $0.79 \pm 0.03$ \\
5 & $109: 16: 1$ & $157 \pm 17$ & $7.2 \pm 0.2$ & $65 \pm 0.8$ & $0.97 \pm 0.01$ \\
6 & $146: 15: 1$ & $192 \pm 10$ & $7.4 \pm 0.2$ & $89 \pm 0.6$ & $0.59 \pm 0.02$ \\
\hline
\end{tabular}

Represented mean values \pm SEM for 5 measurements 
TABLE 2: EFFECT OF EXTRUSION ON AS LIPOSOMES SIZE

\begin{tabular}{lc}
\hline Cycle number & Liposomes average size $(\mathrm{nm}) \pm$ SEM \\
\hline 1 & $270 \pm 12$ \\
2 & $245 \pm 15$ \\
3 & $200 \pm 13$ \\
4 & $189 \pm 11$ \\
5 & $161 \pm 10$ \\
6 & $160 \pm 14$ \\
7 & $153 \pm 13$ \\
8 & $155 \pm 13$ \\
9 & $152 \pm 11$ \\
10 & $153 \pm 15$ \\
11 & $155 \pm 12$ \\
12 & $154 \pm 12$ \\
13 & $150 \pm 16$ \\
\hline
\end{tabular}

Represented mean values \pm SEM for 5 measurements

TABLE 3: ANTITUMOR ACTIVITY OF THE MODEL COMPOSITION OF AS LIPOSOMES

\begin{tabular}{lcccc}
\hline \multirow{2}{*}{$\begin{array}{l}\text { Dose of AHHS } \\
\text { liposomes, mg/kg }\end{array}$} & \multicolumn{4}{c}{ TGI, \% } \\
\cline { 2 - 5 } & $\mathbf{1}$ & $\mathbf{4}$ & $\mathbf{7}$ & $\mathbf{1 0}$ \\
\hline 5 & 69 & 51 & 31 & 21 \\
20 & 82 & 58 & 50 & 33 \\
\hline
\end{tabular}

$\mathrm{P} \leq 0.05$ in comparison to control

dispersion remained unchanged at the initial level, but the $\mathrm{pH}$ decreased from 7.2 to 6.4. Further storage for 3 mo resulted in a precipitate and reduced the $\mathrm{pH}$ to 4.5 , and the concentration of the drug reduced to $14 \%$ of the initial value. These data indicated about the liposomal dispersion instability and the necessity for stabilization by lyophilization process.

Study of antitumor efficacy of liposomal AS was conducted on mice transplanted tumor model, adenocarcinoma Ca-755. It was found that when the liposomal AS was administered at a dose of $5 \mathrm{mg} / \mathrm{kg}$, $69 \%$ TGI was obtained and when administered at the dose of $20 \mathrm{mg} / \mathrm{kg}$, the obtained TGI was about $82 \%$ (Table 3).

While developing the new liposomal AS, a model was established, which contained EL and polyethylene glycol-2000-distearoilfosfatidil ethanolamine in the molar ratio of $72 / 1$, as main components of the liposomal bilayer, and sucrose as a cryoprotector. During the development of technological parameters to obtain the liposomal formulation, it was found that to ensure an acceptable size of derived phospholipid vesicles, about 7 extrusion cycles are needed. The instability of a selected composition of the liposomal dispersion during storage was overcome by lyophilization, kept physical and chemical indicators of the formulation at the initial level. The efficacy of this delivery system on a transplanted breast adenocarcinoma $\mathrm{Ca}-755$ mice tumor model, which was more than $60 \%$ of TGI at $5 \mathrm{mg} / \mathrm{kg}$ and more than $80 \%$ TGI with $20 \mathrm{mg} / \mathrm{kg}$. Findings of this investigation indicated that further research is required to develop this AS liposomal formulation in to a potential antitumor therapy.

\section{Conflicts of interest:}

There is no conflict of interest.

\section{Financial support and sponsorship:}

The investigation was a part of the scientific program "Creation of innovative nanostructured hydrophobic formulation of domestic analogue of hypothalamic hormone somatostatin in the treatment of hormonedependent tumours" under financial support of Russian President's Scholarship.

\section{REFERENCES}

1. Dalm VA, Hofland LJ, Ferone D, Croxen R, Lamberts SW, van Hagen PM. The role of somatostatin and somatostatin analogs in the pathophysiology of the human immune system. J Endocrinol Invest 2003;26:94-102.

2. Danesi R, Agen C, Benelli U, Paolo AD, Nardini D, Bocci G, et al. Inhibition of experimental angiogenesis by somatostatin analog octreotide acetate. Clin Cancer Res 1997;3:265-72.

3. Sanarova EV, Polozkova AP, Meerovich IG, Lantsova AV, Ignateva EV, Orlava OL, et al. Influence of processing factors on the quality of the liposomal form of the new photosensitizer thiosens. Pharm Chem J 2012;45:741-5.

4. Schwendener RA, Schott H. Liposome formulations of hydrophobic drugs. Methods Mol Biol 2010;605:129-38.

5. Hyodo K, Yamamoto E, Suzuki T, Kikuchi H, Asano M, Ishihara H. Development of liposomal anticancer drugs Biol Pharm Bull 2013;36:703-7.

6. Sanarova EV, Lantsova AV, Polozkova AP, Orlova OL, Meerovich IG, Borisova LM, et al. Effectiveness of liposomal system of delivery of hydrophobic antineoplastic thiosens photosensitizer. Nanotechnol Russ 2015;10:492-500.

7. Massing U, Fuxius S. Liposomal formulations of anticancer drugs: selectivity and effectiveness. Drug Resist Updat 2000;3:171-7.

8. Bol'shakov OP, Neznanov NG, Babakhanyan RV. Didactic and ethical aspects of research on biomodels and laboratory animals. Kachestvennaya Klinicheskaya Praktika 2002;1:58-61. 